\section{Biodiversity panel should play by rules}

The Intergovernmental Platform on Biodiversity and Ecosystem Services (IPBES) is adopting its initial work programme for 2014-18. This is a good time to assess whether the "rules of engagement" outlined for its success (E. Turnhout et al. Nature 488, 454-455; 2012) have been put into practice. We find that there are still some serious shortfalls that, unless addressed promptly, could undermine the transparency and credibility of the output from the IPBES.

Some of the nine rules (R1R9; see go.nature.com/guclgk) are now being followed, at least partly: reporting on progress is to be staggered (R8); the call for a decentralized approach that is sensitive to local knowledge, needs and conditions (R1) is now reflected in several deliverables; and most mandated functions are being addressed simultaneously (R2). Cautious optimism is also justified for R3 and R5: expert groups for discussing terms and methodologies are to be established, and nonscientific knowledge systems will be included.

However, non-elite actors are not yet properly involved, and decisions on stakeholder engagement and communication strategies have been postponed, which will affect R3 and R5; this also applies to the inclusion of "trusted civic organizations and networks" (R7).

Furthermore, stakeholders are only marginally involved in nomination procedures for the Multidisciplinary Expert Panel (MEP) and for experts who will work on IPBES deliverables, and are not involved at all in the selection process (R4). Of the MEP members selected, the mix is unbalanced (22 natural scientists, 2 economists and 1 social scientist, and women are under-represented). It is also unclear whether minority dissenting views will be incorporated into the IPBES process (R6). Re-evaluation and improvement of IPBES processes (R9) will be hard because IPBES members have declared that they are not prepared to renegotiate after issues have been formally agreed.

Lars Opgenoorth, Stefan Hotes University of Marburg, Germany. opgenoorth@uni-marburg.de

Harold Mooney Stanford University, California, USA.

\section{Sexual violence rife on US campuses}

Gun violence may be relatively rare on university campuses in the United States (see Nature 505, 150-152; 2014), but other violent incidents are rampant.

Acts of sexual violence, for example, are committed against an estimated $20-25 \%$ of females attending a US college or university (see C. J. Vladutiu et al. Trauma Violence Abus. 12,67-86; 2011). According to the US Census Bureau, roughly $11,658,000$ women were enrolled in higher-education institutions in 2009. Assuming $20 \%$ victimization, as many as 2,331,600 of those could have been sexually assaulted on campus.

You missed an opportunity to expand on a horrifying problem that is all too often underreported.

Stephen Shaffer Endicott, New York, USA.

smshaffe@gmail.com

\section{Scientists need leadership training}

Career scientists need to be able to manage projects, students, postdocs, staff and, ultimately, a scientific team. We suggest that junior scientists should routinely be trained in such leadership skills to maximize the productivity of their future research groups (see also J. C. Seeliger Nature 483, 511; 2012).

Unfortunately, many scientists fail to realize that they need training, and there are only a few leadership programmes on offer. One is the three-day 'Leadership in BioScience' workshop for young investigators held annually by the Cold Spring Harbor Laboratory in New York (see go.nature.com/ocx5yp). Through lectures, role-playing exercises, case studies and discussions, participants learn and practise skills such as setting goals, delivering feedback, running successful meetings and managing conflict or difficult situations that can arise in the laboratory. Training is consolidated with detailed constructive feedback from instructors and other participants.

More such programmes should be developed to help junior faculty members in academic institutions worldwide. Marina Kvaskoff Brigham and Women's Hospital, Boston, Massachusetts, USA. marina.kvaskoff@channing. harvard.edu

Stephanie D. McKay University of Vermont, Burlington, USA.

\section{Cuts threaten future of $R \& D$ in Portugal}

Drastic cuts in public funding for science and technology in Portugal are being applied as part of the government's sweeping austerity measures, without thought for a national long-term science strategy. The effects are particularly hard on young scientists.

The number of $\mathrm{PhD}$ and postdoctoral fellowships awarded by the country's principal funder, the Science and Technology Foundation (FCT), fell by $40 \%$ from 2012 to 2013, and the 2014 budget for fellowships fell by $16.5 \%$ compared with last year.

Coupled with reductions in funding for research centres and research and development (R\&D) projects, these cuts have serious long-term implications for the country's chance of developing a knowledge-based economy.

André Levy ISPA, Lisbon,

Portugal.

andre_levy@ispa.pt

\section{Online repository for lab notebooks}

The US Office of Science and Technology Policy (OSTP) ruled last year that all federally funded research articles and data should be open access, but laboratory notebooks were not included (see go.nature.com/fijt2f). I urge researchers to sign a petition (see http://wh.gov/15gv0) to extend this mandate to cover a searchable online repository of key lab notebooks, such as those used in formulating US patent applications.

The legal value of lab notebooks is complicated, which may be one reason for their omission from the OSTP mandate. However, freely accessible notebooks are useful as evidence in patent litigation and can help to resolve irreproducibility issues that might otherwise have economic and medical implications for products and processes. They also act as an archive of raw data for the scientific and medical record.

As an agency that is fully funded by user fees and one that aims to validate patent findings, perhaps the US Patent and Trademark Office would consider financing the initial purchase of server space and set-up costs for a notebook repository.

Shannon Bohle Lima, Ohio, USA.

sb838@cantab.net

CONTRIBUTIONS

Correspondence may be sent to correspondence@ nature.com after consulting the guidelines at go.nature.com/cmchno. Alternatively, readers may comment online: www. nature.com/nature. 